\title{
They Do Not See Humans
}

\author{
Henry Bair ${ }^{1}$
}

Received: 1 April 2020 / Revised: 8 September 2020 / Accepted: 21 September 2020 / Published online: 8 October 2020

(C) Academic Psychiatry 2020

How do people become so empty?

They see what they want to see.

They do not see humans.

They play a role.

They bend and bow.

How do people become so empty?

Have you seen the serotonin drain from someone while they still move their arms and legs?

They do not see humans.

They only dine on cheap expensive fruits.

They only like this pose because it's comfortable.

How do people become so empty?

They do not smile or weep from a well.

Only do what the pictures tell them.

They do not see humans.

How can we abandon each other? asked the voice with waning dreams.

Instead, they watch coldly as the birds scamper across the dead.

How do people become so empty?

They do not see humans.
Poet's Statement This poem is a villanelle based off of my encounters with a patient battling depression and her expressed feelings of emptiness and disconnection to others. I was particularly struck by the patient's enigmatic trains of thought and her lament of how intensely alone she felt. Using this as a thrust of the poem, I found the villanelle to be apt in capturing the persistence and dispiritedness of this sentiment.

\section{Compliance with Ethical Standards}

Disclosures The author states that there is no conflict of interest.

Publisher's Note Springer Nature remains neutral with regard to jurisdictional claims in published maps and institutional affiliations.

Henry Bair

hbair@stanford.edu

1 Stanford University School of Medicine, Stanford, CA, USA 